\title{
Forma, perspectiva y percepción: ¿es el alma la que ve y no el cuerpo?
}

\section{Form, perspective and perception: is it the soul that sees and not the body?}

\author{
ARIELA BATTÁN HoRENSTEIN \\ CONICET / Universidad Nacional de Córdoba \\ arielabattan@gmail.com
}

Recibido: 04-05-2012

Aceptado: 22-03-2013

\section{Resumen}

En este trabajo se exploran dos modelos de la visión, uno que se apoya sobre la distinción alma-cuerpo y otro que privilegia a un sujeto perceptivo encarnado. El primero de ellos se encuentra desarrollado por R. Descartes en sus escritos sobre óptica, mientras que el segundo encuentra en la filosofía de M. Merleau-Ponty a su más lúcido representante. Intentando una descripción fenomenológica de las experiencias del ver que promocionan cada uno de estos modelos se reflexiona acerca de la relación entre forma, perspectiva y percepción en ocasión de una exposición de arte.

Palabras clave: percepción, alma, cuerpo, fenomenología.

\begin{abstract}
In this paper I try to explore two models of vision, one of them is supported by the distinction between soul and body, the other instead proposes an embodied perceptual subject. The first model of vision is developed by R. Descartes on his writings about Optic, whereas the second model has, as its most clear representative, the French philosopher M. Merleau-Ponty. I would focus on a phenomenological description of the experiences of seeing, which are promoted by each model. I
\end{abstract}


would reflect on the relationship between form, perspective and perception in the context of an art exhibition.

Keywords: perception, soul, body, phenomenology.

\section{Introducción}

En este trabajo me propongo comparar dos modelos de la visión, uno que se apoya en la distinción entre alma y cuerpo y otro que privilegia la experiencia del ver y comprende a la percepción como percepción encarnada. Con el objetivo de llevar adelante esta comparación me serviré de una constelación conceptual conformada por tres nociones: forma, perspectiva y percepción, entendiendo que en cada una de ellas, en particular y en conjunto, es posible realizar la constatación de los cambios en los modelos. Entiendo que es posible reconocer dos maneras diferenciadas e identificables de asumir el fenómeno de la visión, una que es posible atribuir a R. Descartes, en especial en su tratado sobre óptica, otro que tiene a M. MerleauPonty como su principal representante. Forma, perspectiva y percepción son precisamente elementos escogidos para esta constelación conceptual por su estrecha vinculación con el fenómeno de la visión. Este ha sufrido cambios con el paso del tiempo y el transcurrir de la historia que pueden ser constatados por las distintas combinaciones suscitadas en la constelación conceptual propuesta.

A continuación me interesa, antes que ocuparme de la génesis de los conceptos o de las cosmovisiones, concentrar la atención en la manera en que esa constelación se dinamiza en función del ver en el contexto de lo que he denominado el modelo encarnado de la percepción que permite al sintiente y al sensible abandonar los lugares y roles que el modelo cartesiano de la visión les había asignado.

Si es el alma la que ve, tal como reza el dictum cartesiano, entonces la forma y la perspectiva son el arreglo que la geometría natural impone al objeto visto y en consecuencia la percepción es un juicio. Si es el cuerpo el que ve, la forma habita en la propia experiencia perceptiva y la perspectiva es el índice existencial de la percepción, mi punto de vista y modo de acceso privilegiado al mundo. Contrastando estos dos puntos de partida, intentaremos una fenomenología del ver. Para ello me remitiré, de manera ocasional en el curso de estas reflexiones, a una particular y situada experiencia del ver acontecida durante la visita a una exposición de arte1.

\footnotetext{
1 Se trata del ciclo Saturnalia curado por Andrea Ruiz que constó, entre otros, de la muestra Tumbe Runde, ¿lo bello es bueno? que tuvo lugar en el año 2009 en el Centro Cultural España Córdoba, Córdoba, Argentina. En esa oportunidad se reunió la obra de jóvenes artistas con la intención de reflexionar sobre la experiencia de la mirada. A partir de esa muestra y la interacción con los artistas surgieron las ideas iniciales del presente trabajo. De ahí la importancia de referirme a esa muestra y en particular a una obra.
} 


\section{Agentes perceptivos civilizados}

Entro en la habitación donde tiene lugar la exposición, lo hago ataviada de circunstancias, estas son la interrupción de la "actitud natural"2 y el hecho, precisamente, de que me encuentro en una muestra de arte, los objetos que me rodean están, en este contexto, investidos de una significación especial, la del "objeto artístico". Estos objetos, por su condición, exigen de mí una mirada atenta, escrutadora, juiciosa, contemplativa, o incluso (aunque no se trata de mi caso) una mirada taxonómica motivada por alguna suerte de virtus clasificatoria.

Somos agentes perceptivos civilizados, domesticados, si entramos a un museo lo hacemos buscando el sentido en la materialidad oleosa, acuosa o escultórica del elemento y sustancialidad en la superficie que soporta formas y colores. Ahora bien, ¿cómo sería ver sin tantas circunstancias y condicionamiento rondando el fenómeno de la percepción? Esta pregunta anima el intento de una fenomenología del ver, entendida como una descripción de ese fenómeno perceptivo que nos instala en el mundo y hace que ciertos objetos existan para nosotros de una determinada manera, tal cuál se nos dan, es decir en su aparecer. Esta fenomenología no tiene que ser exclusiva del "ver objetos artístico o estéticos"; muy por el contrario, es aplicable a cualquier objeto, a cualquier paisaje, incluso a los rostros y comportamientos de las personas que nos rodean. La diferencia en cada uno de los casos residirá más bien en las imposiciones y urgencias que dominan el ver cotidiano, las cuales, de buena gana, estamos dispuestos a colocar en suspenso cuando entramos a un museo o nos disponemos a apreciar una obra de arte.

Volvamos a la exposición, avanzo por la sala, me detengo ante un objeto determinado y me pregunto, ¿qué es lo que me atrajo?, ¿por qué me detuve aqui y no más allá?, ¿aquello que como espectador me convoca es la significación, el concepto, que adivino como inspiración intelectual del artista o, simplemente, la disposición de forma, materia y color que explota ante mis sentidos?, ¿es el alma la que ve o es el cuerpo el que lo hace?

En el siglo XVII, más precisamente en 1637 año de publicación del Discurso del Método, el filósofo francés R. Descartes zanjaba este interrogante afirmando que es el alma la que ve y no el cuerpo. Las razones con que justificaba su respuesta no eran de orden metafísico, sino una simple constatación empírica. Se puede observar, decía, que cuando el alma está extasiada o distraída por una fuerte contemplación todo el cuerpo permanece sin sentimiento, incluso cuando está siendo tocado por algunos objetos ${ }^{3}$. Esto significa que si el alma no dirige su atención al

\footnotetext{
2 Me refiero con esto a la familiaridad que caracteriza nuestro estar en el mundo, sus creencias y formas de actuar en función de la habitualidad y la certeza que hemos ido adquiriendo mediante la educación formal y no formal, el discurso científico, nuestra inherencia en una cultura y contexto social, etc. 3 Descartes, R. Oeuvres de Descartes, La Dioptrique, Vol. VI, C. Adam et P. Tannery, Paris, Vrin, 1964-1976, p. 109.
} 
órgano de los sentidos que está siendo afectado sensorialmente, no se produce percepción alguna. No es un dato menor que la obra en la cual Descartes hace estas declaraciones sea la Dióptrica, un tratado científico-técnico que acompaña al Discurso del Método y está dedicado al estudio del sentido de la vista y al desarrollo de las técnicas que puedan acrecentar su poder, es decir, a la óptica. Sin embargo, es importante señalar que Descartes hace en la Dióptrica mucho más de lo que declara, pues, además de lo mencionado, diseña un modelo de la visión que viene a poner en tela de juicio al precedente, en el cual seguramente él se formó. Me refiero al modelo renacentista, estableciendo así una nueva concepción de la percepción indiscutida para la posteridad.

Descartes incorpora al estudio de la óptica, conocida con el nombre de perspectiva naturalis, lo que antes era sólo objeto de preocupación de los pintores, es decir, la perspectiva artificialis o el estudio de la representación pictórica, volviéndose así un tema de interés y preocupación para la reflexión filosófica. La perspectiva artificialis de los pintores que consistía, principalmente, en una herramienta geométrica de representación (tal como, por ejemplo, el velo o la rejilla) es reintroducida a partir del s. XVII en el estudio de la percepción sensorial, haciendo aparecer así un nuevo sentido del término "perspectiva", es decir, aquello a través de lo cual se ve4.

En el marco filosófico dentro del cual se desarrolla esta concepción científica de la percepción, el alma y el cuerpo son definidos como naturalezas diferentes y, hasta cierto punto, irreconciliables. Sin embargo, al ser un hecho insoslayable que en el hombre estas dos naturalezas están "ajustadas y unidas", Descartes se vio en la necesidad de desarrollar una compleja arquitectura anatómica y fisiológica para poder explicar la unión circunstancial y contingente de alma y cuerpo. En cuanto determinaciones de la res cogitans y la res extensa, ambas sustancias independientes podían existir de manera separada, el alma en la forma de la inmortalidad y el cuerpo como un autómata de factura divina. Dentro de esta concepción dualista, el modelo cartesiano de la visión constituye, también, un ejemplo del denodado esfuerzo por dar cuenta de la interacción del alma con el cuerpo.

La vista era concebida por Descartes como el más universal y el más noble de todos los sentidos. Esta consideración no resulta novedosa; es más bien una herencia de la tradición neoplatónica del Renacimiento que encontraba semejanzas entre la visión y las operaciones anímicas. En la construcción metafórica que diseña el Renacimiento entre el alma y el ojo, que tiene como término de comparación a la potencia de la inteligencia humana, aquél no era escogido, de entre los demás órganos de los sentidos, por su estructura anatómica, su binocularidad, o la posibilidad de cancelar el espectáculo de manera voluntaria con solo cerrarse. El ojo, por el contrario, fue escogido en el Renacimiento (en especial por los neoplatónicos) por ser el instrumento sensorial cuyo comportamiento más se asemeja al del alma. El

4 Cf. Panofsky, E. La perspectiva como forma simbólica, Barcelona, Tusquets Editores, 1983. 
ojo no comercia con la materia bruta y no se ve interferido por las cualidades de los objetos. A diferencia de la lengua en el sentido del gusto que se deja invadir por el sabor, el tacto que puede ensuciarse o alterarse con lo que toca o el oído que puede quedar perturbado ante un estímulo estridente, el ojo aparece como inalterable testigo externo, espectador ante un espectáculo del cual no participa, pasivo receptor de "imágenes que revolotean por el aire", se originan en los objetos y mágicamente se trasladan hasta él.

Conocida es la alabanza al ojo, concebido como "finestra dell' umano corpo", que escribe Leonardo Da Vinci en su Tratado de la Pintura. Allí dice: "en circunstancias adecuadas y a la distancia apropiada el ojo se engaña menos que ningún sentido"5, por esa razón merece ser llamado el rey de los sentidos y más adelante agrega, "ventana del cuerpo, que a través de él refleja del mundo la belleza y goza de ella; por su intermedio se contenta el alma en su prisión humana; que sin él no sería más que tormento, por su intermedio descubrió el fuego la mano humana, gracias al cual recupera el ojo lo que las tinieblas antes le arrebataron”. El ojo, en opinión de Leonardo, supera incluso a la naturaleza pues esta crea cuerpos finitos, mientras que, gracias a la intermediación de la visión, el pintor es capaz de reproducir formas infinitas6.

Sin embargo, el ojo de los renacentistas no es el mismo que Descartes tiene presente en sus estudios. Si bien es innegable que los pensadores del Renacimiento comparten con Descartes en general una consideración positiva respecto de la visión y sus virtudes, el filósofo francés, a diferencia de aquéllos, se va a esforzar por devolver, por reintegrar, el ojo a la materialidad del cuerpo y, en consecuencia, colocar la visión en el alma. A diferencia de Leonardo, que quiere hacer de la pintura una ciencia de la visión cuyo instrumento privilegiado es el ojo, Descartes pretende contribuir con sus estudios al invento de artilugios que permitan dilatar su poder. La alabanza al ojo de Leonardo es reemplazada en los escritos de Descartes por un conjunto de interrogantes que es preciso responder, por ejemplo, ¿cómo se produce la visión?, ¿cuál es la estructura anatómica del ojo?, ¿qué función desempeña la luz?, ¿cuál es la relación entre la imagen y el objeto? Por otro lado, en el modelo cartesiano de la visión la analogía entre la visión y la inteligencia es sustituida por otra que tiene por objetivo establecer la relación entre la visión y la luz, cobrando así centralidad en la explicación otro sentido, el del tacto. Como bien señala D. Diderot refiriéndose al modelo cartesiano de la visión, "si alguna vez un filósofo ciego y

\footnotetext{
5 Da Vinci, L. Tratado de la pintura (trad. de R. Galvano), Buenos Aires, Ediciones Libertador, 2006, p. 18.

6 Ibidem, p. 35. Resulta interesante señalar que estas comparaciones entre la obra de la naturaleza y la obra del pintor se encuentran enmarcadas en la disputa acerca de la superioridad de las distintas disciplinas artísticas. Leonardo va a sostener y en consecuencia tratar de defender la superioridad de la pintura por encima de la poesía.
} 
sordo de nacimiento hiciera un hombre a imitación del de Descartes, os puedo asegurar..., que situaría el alma en la punta de los dedos; porque es ahí de donde le vienen sus principales sensaciones y todos sus conocimientos"7.

El tacto, como modelo de la visión es presentado por Descartes según el ejemplo del ciego y su bastón. El bastón es el medio gracias al cual la persona no vidente puede deducir tanto la figura del objeto como así también su lejanía o cercanía relativas. En la visión, el movimiento y disposición de las partículas que se genera en el ojo, por causa del objeto con la intervención de la luz, cumplen la misma función que la resistencia ofrecida por los objetos circundantes al entrar en contacto con el bastón. Esta función es, pues, la de informar acerca de la presencia corporal de esos objetos y de sus características geométrico-mecánicas, tales como la distancia, la figura, el movimiento, el tamaño, la dureza, etc. Según Descartes, se puede decir que el ciego "ve" con las manos y el bastón es una suerte de sexto sentido dado para reemplazar al de la vista:

Y para hacer una comparación con eso, -dice- os propongo que penséis que la luz en los cuerpos que llamamos luminosos no es otra cosa que cierto movimiento o una acción muy rápida y vívida, que llega a nuestros ojos por medio del aire y de otros cuerpos transparentes, de la misma forma como el movimiento o la resistencia de los cuerpos, con los que se encuentra este ciego, pasa hacia su mano a través del bastón. ${ }^{8}$

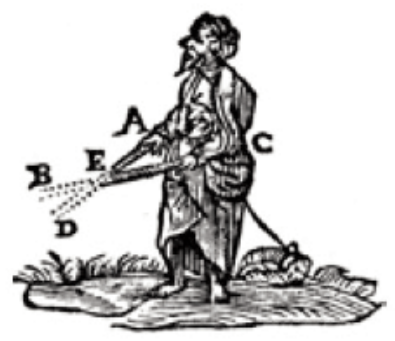

Si las dos manos sostienen cada una un bastón con los que toca un objeto que se encuentra en la intersección de los dos bastones, aunque ignore la longitud de ellos, al conocer la distancia que hay entre las dos manos, así como la medida de sus ángulos, podrá conocer dónde está el objeto.

Este modelo busca diferenciarse del precedente y para ello no sólo debe, como se señaló antes, devolver al ojo su materialidad, su estructura, sus humores y sus nervios, sino que precisa, además, "devolver la materialidad" al objeto de la visión. Esto lo logrará dotando al mundo de propiedades geométrico-mecánicas y convirtiendo a éstas en los verdaderos objetos de los sentidos y la percepción.

\footnotetext{
7 Diderot, D., Carta sobre los Ciegos seguida de Carta sobre los Sordomudos, Trad. de J. Escobar, Valencia, Editorial Pre-Textos-Fundación Once, 2002, p. 23.

8 Descartes 1964-1976, op. cit. (nota 3), p. 84.
} 
El ojo en el modelo cartesiano de la visión va abandonando la metafórica definición de "ventana del alma", para quedar más bien fijado en su significación a la definición de la cámara oscura 9 . Este artificio, un antiguo instrumento utilizado para dibujar, a partir del siglo XVII servirá también como modelo para ilustrar el funcionamiento del ojo y la visión. La cámara oscura consistía en una caja o una habitación con un agujero estratégicamente ubicado en el centro en una de sus paredes por donde penetraba la luz. Frente al agujero se colocaba una lente de manera tal que pudiera proyectar una determinada imagen, la que se pretendía copiar, en la pared posterior de la cámara. En el uso analógico de la cámara oscura el agujero por donde ingresa la luz es comparable con la pupila del ojo humano.

El encuentro del ojo y el objeto no consiste para Descartes más que en un efecto mecánico del choque de partículas y es precisamente a eso a lo que denomina sensación. La sensación en la concepción cartesiana de la visión se limita a ser el producto del contacto de dos cosas extensas con propiedades geométrico-mecánicas, por esa razón, en este nivel eso no constituye todavía una verdadera experiencia visual o percepción. Para que haya visión resulta necesaria la intervención del alma, pues ésta, que se encuentra repartida en todo el cuerpo pero que tiene su sede en el cerebro, es la que ve y no el cuerpo. Es el alma la que ante un cuadro o un grabado distingue escenas de batallas o paisajes, la que en presencia de un objeto cotidiano o de un espectáculo, estipula las distancias y considera las figuras, es decir, interpreta las sensaciones producto de un mero contacto material.

Esto explica la necesidad de Descartes de vincular el fenómeno de la percepción con el de la perspectiva artificialis o representación. El contacto sensorial con el mundo consiste en el encuentro de partículas en movimiento, que impactan por efecto de la luz, con la superficie de los órganos de los sentidos. El efecto de esto la imagen, es decir, la "representación" de los objetos. En el modelo cartesiano de la percepción la única que está en condiciones de decodificar esta representación es el alma. Dice Descartes:

...vemos que los grabados, no habiendo sido realizados sino con una pequeña cantidad de tinta esparcida en diversos puntos sobre un papel, nos representan selvas, villas, hombres e incluso tempestades, aunque de una infinidad de detalles que nos hacen concebir, no exista alguno, con excepción de la figura, en el que propiamente guarden parecido; aun en esto la semejanza es muy imperfecta puesto que sobre una superficie totalmente plana nos representan los cuerpos más adelantados o hundidos, a la vez que siguiendo las reglas de la perspectiva, representan los círculos mediante elipses y no por otros círculos, los cuadrados mediante rombos y no por otros cuadrados y así con otras figuras...10

\footnotetext{
9 Descartes dedica el Discurso V de la Dióptrica a establecer esta comparación.

10 Descartes 1964-1976, op. cit. (nota 3), p. 113.
} 
De igual modo, las sensaciones son las que dan al alma la ocasión de ver tal o cual objeto, de distinguir tal o cual color, sin que haya nada en el objeto que se le asemeje.

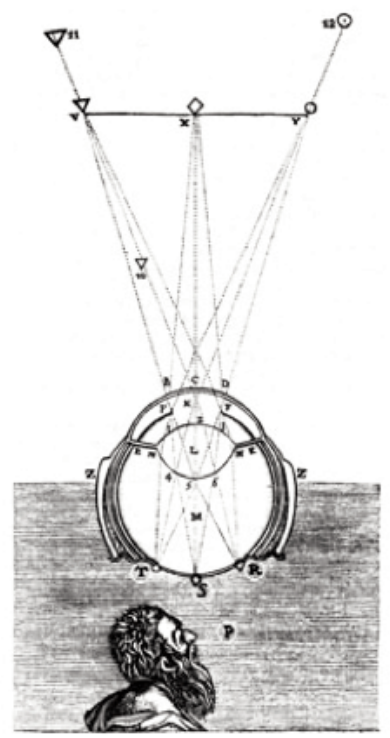

El personaje de este dibujo ha sido interpretado como el filósofo y también como el alma, es importante señalar que lo que ve son figuras geométrica un rombo, un círculo y un triángulo. ${ }^{11}$

Forma, perspectiva y percepción dependen del alma en el modelo cartesiano de la visión, y, si bien no es posible afirmar que sean autónomos respecto del cuerpo, pues toda sensación comienza en sus órganos y miembros, sí se puede aseverar que es el alma la que ve entendiendo, en consecuencia, que ver es un acto de interpretación intelectual. Este acto está garantizado, según Descartes, por una suerte de geometría natural, la cual es una disposición del alma, instituida por Dios, que nos "proporciona el espacio estructurado a cuyo régimen ordenador se someten todos los objetos abarcados por nuestro horizonte visual"12, por virtud de esta geometría natural los objetos pueden ser objetos percibidos.

\footnotetext{
11 Esta ilustración se encuentra entre otros lugares en Descartes, ibidem, p. 116.

12 Velázquez Zaragoza, A., «Perspectiva y representación en el arte y en el conocimiento del velo o "rejilla" del pintor renacentista a la Dióptrica de Descartes», en L. Minhot, L. y Testa, A. (eds.), Representación en Ciencia y Arte, Córdoba, Editorial Brujas, 2003, pp. 279-287, p. 286.
} 


\section{Agentes perceptivos perturbados}

Podemos preguntarnos a continuación y con la finalidad de complejizar el análisis, ¿qué sucede en la alucinación, en la enfermedad o durante ese estado de duermevela que se produce entre el sueño y la vigilia cuando el alma está turbada?

Continú en la exposición mirando los objetos que me rodean, ¿cómo sería ver si mi cuerpo fuera de vidrio? Sin pretender arrogarme originalidad alguna con esta suposición, especulo sobre una posibilidad o, más bien, intento representarme lo que al pobre Tomás Rodaja13 lo tenía tan afectado después del hechizo de una amante despechada que lo dejó creyendo que su cuerpo era de vidrio. ¿Qué sucedería si mi cuerpo no funcionara como la cámara oscura de mi pupila, sino como un cuerpo transparente que deja pasar la luz?

En el caso del Licenciado Vidriera, el propio personaje de Tomás Rodaja en la novela ejemplar de M. de Cervantes, las consecuencias de este hecho fueron sumamente extrañas. Al encontrarse bajo el efecto del hechizo se convenció de que la sutileza material del vidrio le daba a su alma una ligereza y vivacidad poco comunes y le permitía disertar con agudeza de filósofo sobre distintas materias, de alguna manera se había vuelto más sabio. Sin embargo, en lo que se refiere a la percepción sensorial, pensaba el Licenciado Vidriera que el mundo se había convertido en un lugar lleno de peligros para el frágil continente de esa alma.

El testimonio literario de Cervantes cumple en este contexto con un doble propósito, en primer lugar y, tal como lo mencionaba al comenzar este apartado, nos permite complejizar el estado de los agentes perceptivos civilizados. Esto coincide con la opinión de C. Castoriadis quien afirma que “... un mundo sin delirio es una fabricación filosófica incoherente"14. En segundo lugar permite introducir un nuevo aspecto al análisis y es el que resume Diderot en el siguiente párrafo: “...nunca he dudado que el estado de los órganos y de los sentidos tiene mucha influencia sobre nuestra metafísica y nuestra moral, y que nuestras ideas más puramente intelectuales $[\ldots]$ están muy relacionadas con la conformación de nuestro cuerpo..."15.

Otro caso de perturbación al que podemos recurrir en este recorrido para pensar la experiencia del ver desde un lugar más familiar y conocido es el estado intermedio que se produce entre el sueño y la vigilia, por ejemplo, en el despertar. Resulta común en ese estado que la somnolencia nos ofrezca algún objeto cotidiano con apariencia fantasmagórica o que la atmósfera de ensoñación cubra la habitación de un tinte especial. Ahora bien, cuando esto sucede ¿la percepción visual debe espe-

13 Personaje central de la obra de Cervantes El Licenciado Vidriera publicada en 1613. Cervantes, M. de Novelas ejemplares, Madrid, Gredos, 1969.

14 Castoriadis, C., Hecho y por hacer. Pensar la imaginación (trad. de L. Lambert), Buenos Aires, Eudeba, 1998, p. 194.

15 Diderot, op. cit., (nota 8), p. 18. 
rar la corrección anímica?, ¿la experiencia perceptiva es susceptible de arreglo? o ¿es el propio cuerpo el que en el despertar va descubriendo los objetos y develando los fantasmas?

En las primeras páginas de En busca del tiempo perdido es posible encontrar algunas respuestas a estos interrogantes. Allí Marcel Proust relata la experiencia del despertar y cómo se produce esa transición del sueño a la vigilia.

Bajo los presupuestos de una concepción que representa el problema alma-cuerpo según la ecuación dualista en una operación que identifica "alma" y "hombre" y deja sumido en la incógnita, como un tercer término irreconciliable, al cuerpo, la experiencia del despertar posee importantes connotaciones que se hacen visibles incluso en el uso común del lenguaje. En este caso el despertar está vinculado con el "cobrar conciencia" o "recuperar la conciencia", la cual se perdería o desvanecería durante el sueño. Sin embargo, es interesante ver cómo en un breve pasaje Proust logra describir esta misma experiencia del despertar en el dominio restringido del cuerpo, aunque, cabe aclarar, no se trata ya de un cuerpo cartesiano. En el párrafo aludido, el personaje al despertar va evocando y repasando ociosamente todas las alcobas habitadas alguna vez para llegar finalmente a reconocer el lugar en que se encuentra.

Mi cuerpo - dice Proust- demasiado torpe para moverse, intentaba, según fuera la forma de su cansancio, determinar la posición de sus miembros para de ahí inducir la dirección de la pared y el sitio de cada mueble, para reconstruir y dar nombre a la morada que lo abrigaba. Su memoria de los costados, de las rodillas, de los hombros le ofrecía sucesivamente las imágenes de las varias alcobas en que durmiera...16

La descripción de Proust nos coloca sobre una pista segura para considerar en qué consiste la percepción encarnada en la que el cuerpo no sólo no se distingue de la conciencia sino que es, además, su medio de realización y expresión.

Prosigue Proust:

... antes de que mi pensamiento, que vacilaba en el umbral de los tiempos y de las formas, hubiese identificado, enlazado las diversas circunstancias que se le ofrecían, el lugar de que se trataba, el otro, mi cuerpo, se iba acordando para cada sitio de cómo era la cama, de dónde estaban las puertas, de adónde daban las ventanas, de si había un pasillo y, además, de los pensamientos que al dormirme allí me preocupaban y que al despertarme volvía a encontrar. 17

16 Proust, M., En busca del tiempo perdido. Por el camino de Swann, Trad. P. Salinas, C. S. Ediciones, Buenos Aires, 1995, p. 12.

17 Ibidem, p. 12. 
En el caso señalado, el despertar es, de manera simultánea, un acto de orientación espacial, de evocación o rememoración y de percepción. En la medida en que el soporte de estas acciones es el cuerpo no hay posibilidad de aislarlo, a menos que se trate de un recurso analítico, pues recordar y percibir son actividades realizadas por el cuerpo como potencia perceptiva, rememorativa, espacializante. Cuando Proust menciona las imágenes que se suceden, previo a la orientación definitiva, no se refiere a ellas como los vestigios de un pasado, conservados intactos, por la memoria en cuanto función del alma. Por el contrario, todo parece indicar que es la propia capacidad rememorativa del cuerpo la protagonista de esta escena.

El tercer caso que me interesa considerar es el de la enfermedad. En la experiencia mórbida, el cuerpo se convierte en una suerte de pantalla entre el que ve y los objetos, una pantalla que vuelve borrosos los contornos de las formas o distorsiona los objetos como en el caso de la miopía o que alarga las figuras, por efecto del astigmatismo, como en los famosos casos de A. Modigliani y El Greco. La enfermedad proporciona un ejemplo elocuente para entender esta otra dimensionalidad del ver que se realiza en una conciencia encarnada. En la medida en que el cuerpo se convierte en una pantalla entre el sujeto y el mundo, revelándolo de una determinada manera (borroso, atemorizante, deshumanizado, resplandeciente, etc.) no es posible reducir ese estado a un simple condicionamiento transitorio, pues, en la experiencia de la enfermedad tal estado apresa al agente y reconfigura de forma completa y total su existencia.

La enfermedad, sus limitaciones y sus posibilidades, nos alertan sobre la certeza de la encarnación. Ante la experiencia de la enfermedad nos volvemos completamente cuerpo y esto nos permite valorar de manera diferente ese índice de contingencia y facticidad que, según veíamos en el modelo cartesiano, le tocaba al alma corregir como última y decisiva instancia en el proceso perceptivo. En un modelo que privilegia la percepción encarnada no hay lugar para un alma que enmiende o rectifique el contacto fenoménico con el mundo.

\section{Agentes perceptivos encarnados}

Después de la alucinación, los fragmentos de Proust acerca del despertar y la enfermedad en los cuales vimos insinuarse la dimensión corporal de la experiencia perceptiva, será necesario volver sobre los términos de la constelación propuesta para redefinirlos en función de un nuevo punto de partida. Ese nuevo punto de partida es que toda percepción es percepción encarnada, esto es, ocurre y se realiza "en" y "por" el cuerpo propio, el cual es nuestro medio privilegiado de acceso al mundo y a los objetos, entendidos estos en su doble aspecto al ser materiales (esto es, objetos físicos, con una existencia espacio-temporal) y fenomenales o plenos de 
sentido (en la medida en que son para alguien, aparecen a un sujeto y lo hacen de una manera determinada, pues pertenecen a una cultura, se encuentran en un contexto, se usan, se desechan, se aprecian, etc.).

Será otro francés, Maurice Merleau-Ponty, quien entrado el siglo XX encuentre la clave para superar el modelo cartesiano de la visión. Este filósofo se ocupó en sus obras de describir con detenimiento el fenómeno de la percepción y reflexionar acerca de las consecuencias del modelo cartesiano. Consciente de las limitaciones del modelo precedente y de lo íntimamente imbricado que éste se encontraba en las creencias más primitivas y comunes y, en general, en la cultura compartida, eligió el estudio de la experiencia en la enfermedad como una manera de evadir estas determinaciones teóricas y poder aprehender el fenómeno de la percepción en su verdadera dimensión. Afirma Merleau-Ponty, en Estructura del comportamiento, en relación a la experiencia de la enfermedad y del papel que esta juega en la existencia humana,

Cuando las particularidades corporales irremediables se integran en el conjunto de nuestra experiencia, dejan de tener en nosotros la dignidad de causa. La anomalía visual puede recibir, por meditación del artista, una significación universal y convertirse para él en la ocasión de percibir uno de los «perfiles» de la existencia humana. Los accidentes de nuestra constitución corporal pueden siempre desempeñar ese papel de reveladores, a condición de que, en lugar de ser sufridos como hechos puros que nos dominan, se conviertan, por la conciencia que de ellos tomamos, en el medio de extender nuestro conocimiento.

Y continúa, haciendo referencia concreta a la anomalía visual que padecía El Greco:

En el límite, el supuesto trastorno visual del Greco ha sido dominado por él y tan profundamente integrado en su manera de pensar y de ser, que aparece, en fin, como la expresión necesaria de su ser, mucho más que como una particularidad impuesta desde fuera. 18

Ahora bien, si colocamos en el centro de la constelación conceptual propuesta al cuerpo tal como lo vivimos, llamado por Merleau-Ponty fenomenal o propio, ¿en qué aspectos se modifica la experiencia del ver?

La fenomenología de Merleau-Ponty elabora a partir de la distinción husserliana entre Leib y Körper (los términos en alemán para referirse al cuerpo como unidad orgánica y biológica, por un lado, y al cuerpo como unidad de sentido que es nuestro punto de inserción en un mundo de cosas y sujetos) la noción de cuerpo propio o fenomenal en oposición al denominado cuerpo objetivo, es decir, aquél que la filo-

18 Merleau-Ponty, M., Estructura del comportamiento, Trad. E. Alonso Buenos Aires, 1976, p. 281 s. 
sofía y la ciencia construyen con sus discursos. El cuerpo fenomenal no posee en el contexto de Fenomenología de la percepción, obra central del pensamiento merleaupontyano, un carácter instrumental; no es un concepto ni una categoría, se trata más bien de un resto, el que queda una vez que se ha contrastado eso que, por ejemplo, la fisiología dice acerca de mi cuerpo y la propia experiencia de la corporeidad en la enfermedad, en la sexualidad, en la expresión. Es una relación ambigua la que vincula la experiencia y el pensamiento objetivo, pues este se apoya en aquella, pero la niega en pos de los ideales de neutralidad y universalidad exigidos para el conocimiento científico, instalados en éste, sostiene Merleau-Ponty, "ya no me ocupo más de mi cuerpo, ni del tiempo, ni del mundo, tal como los vivo en el saber antepredicativo, en la comunicación interior que con ellos tengo. No hablo de mi cuerpo más que en idea, del universo en idea...". El pensamiento objetivo "nos hace perder el contacto con la experiencia perceptiva de la que es resultado y consecuencia". 19

Vuelvo a la exposición. Me he detenido frente a un objeto ${ }^{20}$, pende del techo y no logro abarcarlo intelectualmente, "no sé lo que es", sin embargo no puedo decir que no lo "comprenda", de alguna manera el objeto sabe significar y esa significación está dirigida a mi cuerpo. La aspereza cálida de la urdimbre, la invitación a transitarlo que sugieren las rayas blancas y amarillas (que no son sólo eso, justamente porque son signos), la posibilidad de rodearlo, de mirar a través de él, e incluso la posibilidad de ocultarse en él, son "significaciones" que me da mi cuerpo. ¿De qué manera este objeto habita el espacio?, ¿de qué manera lo habita mi cuerpo?

Mi cuerpo no es una cosa-en-el-espacio, no tiene una espacialidad de posición, sino más bien de situación ${ }^{21}$. La situación se caracteriza y diferencia de la posición, pues no establece un lugar en el espacio, un punto designable, sino que irradia espacialidad y establece recorridos posibles, zonas vedadas, funda el arriba y el abajo, el adentro y el afuera, el delante y el detrás. La espacialidad de situación sobreentiende un cuerpo activo y a su entorno como el conjunto de coordenadas para posibles acciones. Así, la espacialidad del objeto también se modifica como consecuencia y efecto de la redefinición de la espacialidad del cuerpo propio. La cosa vista se transforma de esta manera y se convierte, antes que en un objeto que ocupa un lugar en el espacio, en eso que está al final de mi exploración, que es deseable o alcanzable en función de mi situación y de mis posibilidades. La cosa es introducida

\footnotetext{
19 Merleau-Ponty, M. Phénoménologie de la Perception, Vrin, Paris, 1945, p. 85 s.

20 Se trata de la obra Oro en el viento del artista plástico Guido Yanitto. Es posible encontrar fotografías de ese objeto, que en la muestra pendía del techo, en otras variantes performáticas organizadas por su autor en el siguiente enlace: http://guidoyannitto.blogspot.com.ar/search?updated-max=2010-1024T15:06:00-07:00\&max-results=10. Agradezco al artista por permitirme compartir imágenes de la obra en este trabajo.

21 Cf. Merleau-Ponty 1945 (nota 20), p. 116.
} 
mediante la percepción en el sistema práctico que se diagrama entre mi cuerpo y el espacio.

Dentro de este modelo de la percepción encarnada se tranforman de manera simultánea las nociones de forma y perspectiva. En primer lugar, la noción de forma pierde toda connotación intelectual en la medida en que deja de ser un objeto identificable para una conciencia o una determinación exclusiva de la materia. La "forma", como tal, sólo tiene existencia en una experiencia perceptiva. Esta reinstalación de la forma en la experiencia, es también efecto del descubrimiento del cuerpo fenomenal por obra de Merleau-Ponty22. Esto no significa ni supone que el mundo de los objetos pierda sus propiedades geométricas; éstas, por el contrario, ocupan un lugar en la nueva constelación, sólo que no son concebidas ni como propiedades últimas de la materia, ni tampoco puede decirse que su conocimiento se reduzca a sus propiedades. Las llamadas propiedades geométricas de los objetos son el producto de una determinada operación categorial que busca en el mundo regularidades, coordenadas y funciones. Lo que el modelo encarnado pone de relieve es la dependencia de la operación categorial respecto de la percepción, incluso podría enfatizarse esta afirmación diciendo que no sólo depende sino, más bien, se funda en ella. Es en la percepción donde la actividad categorial del científico o del filósofo descubre los elementos básicos, los materiales de trabajo, en el encuentro de cuerpo y mundo. De esta manera se logra poner en evidencia que la ciencia, esto es la construcción categorial del mundo, opera un engaño fundacional al colocar la percepción a posteriori, como aquello que necesita ser subsanado, corregido o enmendado. Merleau-Ponty se pregunta entonces, no sin cierta ironía,

\begin{abstract}
¿No consistió el progreso del saber, en olvidar lo que nos dicen los sentidos ingenuamente consultados y que no tiene lugar en un cuadro verdadero, sino como una particularidad de nuestra organización humana de que la ciencia fisiológica dará cuenta un día, como ya explican las ilusiones del miope y del présbite? El mundo verdadero no son esas luces, esos colores, ese espectáculo de carne que me dan mis ojos; son las ondas y los corpúsculos de los que me habla la ciencia y que se encuentra tras esas fantasías sensibles. ${ }^{23}$
\end{abstract}

Por el contrario, la posibilidad del conocimiento está dada por la instalación de un cuerpo que transforma los "datos del mundo" en significaciones en la medida en que se someten a una "deformación coherente", es decir, que son aprehendidos desde ciertas condiciones de existencia, desde determinada perspectiva, desde una situación. La percepción, en la medida en que es protagonizada por el cuerpo y no

22 Cf. Barbaras, R. De l'être au phénomène. Sur l'ontologie de Merleau-Ponty, Grenoble, Jêrome Millon, 1991.

${ }^{23}$ Merleau-Ponty, M., El mundo de la percepción. Siete conferencias, El mundo de la percepción. Siete conferencias, Trad. de V. Goldstein, México, Fondo de Cultura Económica, 2003, p. 10. 
por el alma desencarnada que puede abarcarlo todo con su "mirada" desde ningún lugar, es siempre parcial y perspectiva. Es parcial, precisamente, porque hay aspectos que se le ocultan, porque el objeto no se da como una totalidad, ni siquiera como una suma de partes, sino más bien como aspectos, escorzos, recortes que hacen de lo visto una totalidad momentánea y siempre en riesgo de reconfiguración (como consecuencia del cambio de perspectiva o porque ciertos cuerpos y/o objetos se superponen unos a otros en el campo visual, o por el estado en que se encuentra el sujeto, etc.).

La noción de perspectiva cobra en este modelo de la percepción encarnada una nueva significación superando así los límites de comprensión renacentista. No se trata en este contexto de un medio de representación o del "secreto técnico" de los pintores, no es concebida como un instrumento de organización y jerarquización espacial que permita dominar un paisaje para luego reproducirlo. Tampoco es la perspectiva de la que habla Descartes en la Dióptrica cuando pretende, de manera innovadora, conciliar la perspectiva artificial (como técnica para la representación pictórica) con la perspectiva natural en su estudio de la percepción ${ }^{24}$. Por el contrario la perspectiva en este modelo de la percepción encarnada, antes bien que un hallazgo cultural, es un modo originario de acceso perceptivo, el componente existencial del espectáculo visual. La perspectiva es consecuencia de una determinada estructura de la presencia, de una modalidad de existencia que convoca espacio y tiempo en la corporeidad fenomenal. De modo que, esta perspectiva no puede ser reproducida planimétrica o geométricamente, no puede ser calculada, porque no supone un punto de vista fijo y estático, sino que admite en su trazado y en su identificación las posibilidades de acción y de recorridos, factibles o vedados. La perspectiva ofrece un medio de acceso perceptivo a lo sensible y a lo significativo, al mismo tiempo. De hecho, este modelo de la percepción encarnada no admite esta distinción, sino que más bien, intenta superarla.

En virtud de esto, podemos volver al objeto que atrajo la mirada. Según la "explicación" del artista se trata de un telar, sin embargo, bajo nuestra mirada fenomenológica ha llegado a ser todavía más que eso, un cuerpo maleable, un tejido ancestral, una superficie transitable, un objeto de uso... simultánea y consecutivamente.

\section{Conclusión}

La mirada fenomenológica ha logrado indagar en el fenómeno perceptivo, como fenómeno de sentido, yendo más allá de la actitud natural y la actitud categorial. Ha

\footnotetext{
24 Sobre estas acepciones de la perspectiva se recomienda el estudio de Merleau-Ponty El Ojo y el Espiritu, «L'Oeil et l'Esprit» en Les Temps Modernes, 17 année, n. 184-185. Numéro Spécial, pp. 193227,1960 .
} 
intentado buscar el origen de una y otra en la experiencia perceptiva, para ello hemos apelado al recurso fenomenológico de las variaciones imaginarias. La alucinación, la enfermedad y el sueño nos han revelado la esencia de la experiencia perceptiva, la cual no consiste en la postulación de una conciencia y de un mundo de cualidades entre los cuales hay que establecer vinculaciones, sino más bien en el encuentro espontáneo de una conciencia encarnada y un "mundo de seres que se muestran". 